\title{
Análise físico-química de diferentes amostras de cimento comercializados na cidade de São Luís - Ma
}

\section{Physical-chemical analysis of different cement samples commercialized in the city of São Luís - Ma}

\author{
Manuelle Sá Lobato ${ }^{1}$, Diogo Marcelo Lima Ribeiro ${ }^{2}$, Adriana Marques Silva ${ }^{3}$
}

\begin{abstract}
RESUMO: O objetivo deste estudo foi analisar os diferentes tipos de cimento (CP II-E, CP IV E CP V) para entender o seu funcionamento durante sua hidratação, visando prevenir patologias em estruturas de concreto, e quantificar um dos agentes de grande poder de corrosão, os íons de cloreto em pasta de cimento. A análise consistiu em testes, em laboratório, de $\mathrm{pH}$ em diferentes amostras de cimento, comprovando a alta alcalinidade do mesmo. O teste é feito com a utilização do peagâmetro metrohm, que é colocado o elétrodo na solução já filtrada para a obtenção do valor do $\mathrm{pH}$. Esse $\mathrm{pH}$ alto do cimento é maior responsável pela proteção da armadura da estrutura de concreto, pela criação da película protetora de passivação. Foram realizados testes objetivando medir quantitativamente por precipitação o íon cloreto em diferentes tipos de cimento, uma vez que é um dos principais agentes de corrosão, além de São Luís ter presença constante de salinidade, o que contribui para o surgimento de patologias. E, na sequência, fora medida com termômetro a temperatura alcançada por período de tempo da pasta de cimento, visando-se obter a variação da mesma, causada pela hidratação do cimento.
\end{abstract}

PALAVRAS-CHAVE: Tipo de cimento; cloreto; pH; despassivação; calor de hidratação.

ABSTRACT: The goal of this study was to analyze the different types of cement (CP II-E, CP IV and $\mathrm{CP}$ V) to understand the functioning during the hydration of it, in order to prevent pathologies in structures concrete, and to quantify one of the high corrosion agentes, chloride ions in cement paste. The analysis consisted of laboratory tests of $\mathrm{pH}$ in different samples of cement, proving the high alkalinity of the same. The test was made using the meterhm peag, which is placed the electrode in the solution already filtered to obtain the $\mathrm{pH}$ value. This high $\mathrm{pH}$ of the cement is more responsible for the protection of the reinforcement of the concrete structure, by the creation of the protective film of passivation. The goal of this study was to quantitatively measure chloride ion in different types of cement, since it is one of the main corrosion agents, besides São Luís, it has a constant presence of salinity, which contributes to the appearance of pathologies. And in the sequence the temperature reached by time of the cement paste was measured with thermometer, aiming at obtaining the variation of the same, caused by the hydration of the cement.

KEY WORDS: Type of cement, chloride $\mathrm{pH}$, depassivation, heat of hydration.

\footnotetext{
${ }^{1}$ Egressa do Curso de Engenharia Civil da Universidade Ceuma. E-mail: manuellelobato@ hotmail.com

2 Doutorando da Rede de Biodiversidade e Biotecnologia da Amazônia Legal (BIONORTE), Mestre em Química Analítica pela Universidade Federal do Maranhão, Graduado em Química Industrial pela Universidade Federal do Maranhão. Atualmente é Professor do Departamento de Engenharia Civil e Farmácia da UNICEUMA. Tem experiência na área de Química, com ênfase em Química Analítica, Microbiologia, Controle de Qualidade de Água e Espectrofotometria. E-mail: diogomlr@hotmail.com

3 Professora Esp. do Curso de Graduação em Bacharelado em Engenharia Civil, mestranda em Meio Ambiente, coordenadora geral de curso de Eng. Civil da Universidade CEUMA, Especialista em Engenharia de Segurança e Saúde do Trabalho, Especialista em Engenharia de Produção, Professora das disciplinas de Introdução a Engenharia Civil, Materiais de Construção Civil, Construção Civil I e Construções Verticais da Universidade Ceuma, membro do grupo de pesquisa em Gestão, Conservação e Tratamento de Água do curso de Engenharia Civil da Universidade Ceuma, Parecerista da Revista Guia do Estudante, Editora Abril. E-mails:adriana.marques@ceuma.br, drianamarx.5000@gmail.com
} 


\section{INTRODUÇÃ̃O}

A corrosão do concreto acarreta na estabilidade e durabilidade das estruturas, uma vez que a armadura fica suscetível a sofrer corrosão. Os componentes do concreto são os responsáveis por impedir a corrosão metálica já que se opõem à entrada de contaminantes no aço da estrutura. Por isso é de fundamental importância o concreto se manter inalterado (GENTIL, 2014).

As principais patologias em concreto ocorrem pela lixiviação, carbonatação e o contato com íons de cloreto na estrutura. A lixiviação ocorre primeiramente pela reação da água, com concentrações de sais de cálcio e magnésio, com o hidróxido de cálcio, $\mathrm{Ca}(\mathrm{OH})_{2}$, tornando o concreto poroso. $\mathrm{O}$ contato do hidróxido de cálcio já lixiviado com o dióxido de carbono, $\mathrm{CO}_{2}$, forma o carbonato de cálcio, $\mathrm{CaCO}_{3}$, que é insolúvel, conforme a reação 1 (GENTIL, 2014).

$$
\mathrm{Ca}(\mathrm{OH})_{2}+\mathrm{CO}_{2} \rightarrow \mathrm{CaCO}_{3}+\mathrm{H}_{2} \mathrm{O}
$$

Esta reação acarreta na diminuição o pH do concreto, onde ocorre a despassivação do aço.

$\mathrm{Na}$ carbonatação, ocorre a mesma reação que a anterior, inicialmente, mas na sequência, com o contato ainda com o dióxido de carbono, existente em águas agressivas, o carbonato de cálcio, $\mathrm{CaCO}_{3}$, reage com o dióxido de carbono formando o bicarbonato de cálcio, $\mathrm{Ca}\left(\mathrm{HCO}_{3}\right)_{2}$ que é solúvel, conforme a reação 2, por isso ocorre uma maior deterioração que a anterior, uma vez que o bicarbonato de cálcio é mais solúvel que o carbonato de cálcio $\left(\mathrm{CaCO}_{3}: 13 \mathrm{mg} / \mathrm{l} ; \mathrm{Ca}\left(\mathrm{HCO}_{3}\right)_{2}: 1,890\right.$ $\mathrm{mg} / \mathrm{l})$ (GENTIL, 2014).

$$
\mathrm{CaCO}_{3}+\mathrm{H}_{2} \mathrm{O}+\mathrm{CO}_{2} \rightarrow \mathrm{Ca}\left(\mathrm{HCO}_{3}\right)_{2} \mathrm{O}
$$

Um dos agentes mais agressivos para o concreto é o cloreto $\left(\mathrm{Cl}^{-}\right)$, já que ele diminui a ação da película protetora existente no concreto de passivação que é um meio alcalino. Além de poder diminuir a resistividade do concreto, ajudando o processo eletroquímico de corrosão das armaduras. $\mathrm{O}$ íon de cloreto pode ser acrescentado no concreto de forma involuntária, que são os aditivos com objetivo de acelerar o seu endurecimento, na forma de alta concentrações em seus agregados, areia e água que não podem exceder os valores da norma ABNT NBR 7211, que determina valores percentuais para concreto simples, armado e protendido (HELENE, 1986).

Quando o cimento é hidratado, tem como resultado atingir estados estáveis de baixa energia. Por isso que, durante esse processo, ocorre a liberação de energia em forma de calor, o chamado calor de hidratação, ou seja, ela é uma reação exotérmica. A quantidade de calor gerada por essa reação é diretamente proporcional ao volume; por isso, quando se concretam grandes volumes, são necessárias medidas para abaixar essa temperatura, pois elas aumentam consideravelmente. O risco 
causado por essa elevação da temperatura é a possibilidade de surgimento de fissuras causadas pela dilatação do seu volume por causa essa variação de temperatura, sendo que pode haver aumentos em até $40^{\circ} \mathrm{C}$ acima da temperatura ambiente (TARTUCE, 1996).

A estabilidade dimensional da estrutura de concreto, que são os casos de expansão, fissuração e retração, a resistência química do concreto, ou seja, a capacidade do concreto em resistir a diferentes agentes químicos (água do mar, salinidade do ar, poluição do ar, ácidos entre outros) são interligadas as características físicas e químicas do cimento.

Esta pesquisa objetivou a realização de testes qualitativos e quantitativos, considerando as características físicas e físico-químicas dos diferentes tipos de cimento comercializados em São Luís-MA (CP II-E, CP IV, CP V-ARI), visando prevenir patologias em estruturas de concreto.

\section{MATERIAIS E MÉTODOS}

\subsection{COLETA DAS AMOSTRAS}

A pesquisa foi realizada visando identificar quantitativamente, por meio de teste de laboratório, os íons de cloretos, calor de hidratação e o pH das amostras dos diferentes tipos de cimento, objetivando a prevenção de patologias causadas por esses fatores.

A coleta dos cimentos em análise fora obtida em diferentes localizações. O cimento pozolânico (CP IV) foi encontrado em uma loja de materiais de construções de bairro, já o cimento composto de escória fora coletado no canteiro de obra de uma construtora. $\mathrm{O}$ cimento de alta resistência inicial é o menos utilizado no cotidiano de uma obra, pois apresenta maior valor financeiro, por isso foi encontrada somente em uma loja de grande porte do ramo da construção civil, todos os pontos de coleta localizados na cidade de São Luís-MA.

\subsection{PREPARO DAS AMOSTRAS DE CIMENTO}

No laboratório de Química Tecnológica da Universidade CEUMA, foram preparadas as amostras para realização de ensaios quantitativos, seguindo as etapas:

Inicialmente foi realizada a preparação das amostras para o teste quantitativo de precipitação de cloreto e para determinação do $\mathrm{pH}$ da mesma. O primeiro passo foi pesar $1 \mathrm{~g}$ e $3 \mathrm{~g}$ de cada amostra de cimento na balança de precisão. Na sequência, foram acrescentados $30 \mathrm{ml}$ de água 
destilada com uma proveta, misturando a solução manualmente com ajuda do bastão de vidro.

O material misturado foi filtrado em papel filtro qualitativo com granulometria de $80 \mathrm{~g} / \mathrm{m}^{2}$ e diâmetro de $12 \mu \mathrm{m}$. Por último, foi realizada a identificação das amostras nos Erlenmeyers. Realizou-se os testes em triplicatas.

Para a análise da temperatura alcançada pela hidratação da pasta de cimento, fora pesado na balança de alta precisão $20 \mathrm{~g}$ e $40 \mathrm{~g}$ de cada amostra, sendo acrescido $10 \mathrm{ml}$ e $20 \mathrm{ml}$ de água destilada respectivamente, e misturado manualmente com o bastão de vidro.

\subsection{ENSAIO QUANTITATIVO de $\mathrm{pH}$}

Para os ensaios foi utilizado o peagâmetro de bancada da marca Metrohm, modelo 827 pH lab, para obter o valor preciso do $\mathrm{pH}$. O método consiste basicamente em posicionar o eletrodo do peagâmetro nas amostras filtradas dos diferentes tipos de cimento. De uma amostra para outra necessitou-se realizar a limpeza desse eletrodo com água destilada, evitando interferência nas outras amostras.

\subsection{ENSAIO QUANTITATIVO DE PRESENÇA DE CLORETO}

O ensaio quantitativo de presença do cloreto, também conhecido como método de MOHR, detecta o ponto final por colorimetria numa volumetria de precipitação de uma solução de cloreto das amostras dos cimentos, com a solução de Nitrato de Prata $\left(\mathrm{AgNO}_{3}\right)$ na presença do indicador de Cromato de Potássio $\left(\mathrm{K}_{2} \mathrm{CrO}_{4}\right)$, posteriormente o íon prata combina-se com o cromato formando um segundo precipitado, o cromato de prata, que é na coloração vermelho tijolo, assim indicando o ponto final de precipitação desejado.

A mudança de cor para vermelho tijolo indica que todo cloreto da solução reagiu com a solução de nitrato de prata, portanto com a quantidade de nitrato gasto é possível determinar a quantidade em gramas de cloreto conforme a equação 03:

$$
\mathrm{C}_{\mathrm{AgNO}_{3}} \times \mathrm{V}_{\mathrm{AgNO}_{3}}=\mathrm{m}_{\mathrm{Cl}} / \mathrm{MM}_{\mathrm{Cl}}
$$

Em que:

$\mathrm{C}_{\mathrm{AgNO}_{3}}$ : Concentração de Nitrato de Prata em mol por litro (mol/l);

$\mathrm{V}_{\mathrm{AgNO}_{3}}$ : Volume titulado gasto em litro (1);

$\mathrm{m}_{\mathrm{Cl}}$ : Massa do cloreto em gramas $(\mathrm{g})$;

$\mathrm{MM}_{\mathrm{Cl}}$ : Massa molecular do cloro em gramas por mol (35,453 g/mol);

Para o método sugerido fora utilizado a concentração do nitrato de prata de $0,1 \mathrm{~mol} / \mathrm{l}$. 
Para o resultado da massa do cloreto em gramas, multiplica-se a concentração de Nitrato de Prata $\left(\mathrm{C}_{\mathrm{AgNO}_{3}}\right)$ pela massa molecular do cloro $\left(\mathrm{MM}_{\mathrm{Cl}}\right)$ e volume titulado gasto $\left(\mathrm{V}_{\mathrm{AgNO}_{3}}\right)$, tendo que ser convertido de mililitros para litros, multiplicando por $10^{-3}$, conforme equação 04:

$$
\mathrm{m}_{\mathrm{Cl}}=\mathrm{C}_{\mathrm{AgNO}_{3}} \times \mathrm{MM}_{\mathrm{Cl}} \times \mathrm{V}_{\mathrm{AgNO}_{3}} \times 10^{-3}
$$

Fora utilizado o mesmo processo que o anterior, isto é, diluir $1 \mathrm{~g}$ de cimento em $30 \mathrm{ml}$ de água destilada e, na sequência, filtrada. Foram obtidas 3 amostras e cada amostra fora colocada em Erlenmeyer. Foram adicionadas 4 gotas de cromato de potássio nos Erlenmeyer que mudou sua coloração para amarelo. Na sequência, ocorreu o processo de titulação de nitrato de prata com ajuda de uma bureta volumétrica para medir o gasto da solução de nitrato de prata para atingir a viragem e cor vermelho tijolo.

\subsection{ENSAIO PARA DETERMINAR TEMPERATURA ALCANÇADA PELA HIDRATAÇÃO DO CIMENTO}

Primeiramente, faz-se necessária a determinação a relação água/cimento que foi utilizada a de 0,5 , ou seja, para a cada $100 \mathrm{~kg}$ de cimento, são necessários $50 \mathrm{~kg}$ de água, por exemplo. Utilizando valores menores para produzir em laboratório, foram utilizados inicialmente $20 \mathrm{~g}$ de cimento para $10 \mathrm{ml}$ de água destilada, na sequência foram dobrados os valores para uma melhor análise, $40 \mathrm{~g}$ de cimento para $20 \mathrm{ml}$ de água destilada.

Logo na sequência fora medida a temperatura da pasta de cimento de cada amostra pelo termômetro, e medida novamente a cada 3, 6 e 7 minutos para obter-se essa variação.

\section{RESULTADOS E DISCUSSÕES}

\subsection{ENSAIO QUANTITATIVO DE $\mathrm{pH}$}

As amostras passaram por testes em peagâmetro, no modelo 827 pH lab do Metrohm. Nos ensaios, com soluções de $1 \mathrm{~g}$ de cimento e a com $3 \mathrm{~g}$, todas as amostras apresentaram o pH no intervalo de 11,9 a 12,4, conforme os dados da tabela 1. Isso comprova a alta alcalinidade do cimento, que é o responsável pela criação da película protetora do concreto. 
Tabela 01 - Catalogação de pH das amostras de cimento Portland.

\begin{tabular}{|c|c|c|c|}
\hline \multirow[b]{2}{*}{$\stackrel{0}{B}$} & \multicolumn{3}{|c|}{ pH } \\
\hline & $\begin{array}{l}\text { Peagâmetro - } \\
\text { amostra com } 1 \mathrm{~g} \\
\text { com agua } \\
\text { destilada }\end{array}$ & $\begin{array}{l}\text { Peagâmetro - } \\
\text { amostra com } 1 \mathrm{~g} \\
\text { com agua de poço }\end{array}$ & $\begin{array}{l}\text { Peagâmetro - } \\
\text { amostra com } 3 \mathrm{~g} \\
\text { com agua destilada }\end{array}$ \\
\hline $\begin{array}{l}\text { 章 } \\
\text { 它 }\end{array}$ & 12,00 & 11,99 & 12,25 \\
\hline $\begin{array}{l}z \\
\text { t }\end{array}$ & 12,10 & 12,04 & 12,42 \\
\hline $\begin{array}{l}1 \\
\dot{u}^{\prime} \\
\vec{c}\end{array}$ & 12,07 & 11,98 & 12,39 \\
\hline Média & 12,06 & 12,00 & 12,35 \\
\hline $\begin{array}{c}\text { Desvio } \\
\text { Padrão } \\
\end{array}$ & 0,05 & 0,03 & 0,09 \\
\hline
\end{tabular}

Fonte: Autores (2017).

Nas amostras com a utilização da água de poço, percebeu-se uma diminuição levemente do $\mathrm{pH}$ das amostras, uma vez que, para a água destilada, se obteve um $\mathrm{pH}$ de aproximadamente 9,50. Já na água de poço fora observado um pH de aproximadamente 7,01, tendendo à neutralidade. Por esses fatores, faz-se necessária uma maior preocupação com o controle de todos os componentes do concreto, como o cimento, a água de amassamento, a areia, pois todos irão influenciar no produto final que é o concreto, sendo o pH da água influenciável na base formada na reação de hidratação.

Sabe-se que a água destilada, além de ser cara, em função do seu processo de fabricação, torna-se inviável para amassamento, pois, por não possuir sais, esta iria diluir o hidróxido de cálcio formado, acarretando numa diminuição da resistência do concreto.

Com o objetivo de aumentar a relação água cimento, fora colocado $3 \mathrm{~g}$ de soluto para a mesma quantidade de solvente, no qual se obteve resultados mais elevados para o $\mathrm{pH}$, confirmando uma maior presença dos íons hidroxila, sendo proporcional à amostra utilizada, confirmando assim, a presença do hidróxido de cálcio, formado via reação de hidratação do cimento, sendo responsável pela total passivação do concreto e consequentemente da armadura interna, pois em função deste alto $\mathrm{pH}$, cria-se uma película protetora de óxido metálico.

Comprova-se que, independentemente do tipo de cimento, a alta alcalinidade do concreto é gerada, via reação de hidratação do cimento. 


\subsection{ENSAIO QUANTITATIVO POR PRECIPITAÇÃO}

O ensaio escolhido para determinar quantitativamente os íons totais de cloreto foi o teste de MOHR que utiliza o indicador de nitrato de prata em presença de cromato de potássio. Essa análise foi feita com os diferentes tipos de cimentos, objetivando-se determinar sua quantidade por precipitação. A escolha do método baseou-se na simplicidade e no custo de análise, sendo de rápido resultado, pois é obtido pela colorimetria da solução, ou seja, mudança de tonalidade quando diluído em nitrato de prata.

Os resultados não foram determinantes para quantificar os íons cloreto, pois as concentrações de cloreto em pasta de cimento são pequenas, então não foi possível a formação de precipitados. Quando foi acrescentado o nitrato de prata, a solução não apresentou à coloração almejada, o tom de vermelho tijolo, a coloração apresentou um tom aproximado do verde, além de não ter formado o precipitado. Existem outros métodos que são tradicionalmente utilizados, como o método de Willard e Winter, dissoluções com ácidos, potenciometria com eletrodo íon seletivo (LIBS), entre outros, porém não foi possível suas aplicações, já que esses métodos requerem maior tempo para preparo das amostras, grande número de etapas e custo elevado.

O método de MOHR é eficiente dentro de seu limite de detecção para análises de cloreto em concreto, areia, água, porém, é ineficiente para análise de cloreto em cimento, pois, por mais que o cimento não se apresenta o íon cloreto, a cloração da solução, após o uso de nitrato de prata, teria que ser vermelho tijolo, como dita a técnica, fato este que não aconteceu.

Um modelo de análise de cloreto em cimento com rapidez na sua elaboração e com baixo consumo de reagente, comparado ao método oficial (ASTM C114-11b, extração ácida e determinação pelo método de Volhard), foi estudado por Duarte e colaboradores que determinaram a eficiência do mesmo, o método de pirólise e os métodos espectrofotométricos, com algumas adaptações para essa análise. Consiste, basicamente, na etapa de preparação da amostra, na hidrólise de alguns elementos a altas temperaturas, em torno de $1000{ }^{\circ} \mathrm{C}$ em presença de vapor d' água. Pois quando há presença de alguns elementos como os halogênios, o enxofre e boro são quantitativamente volatilizados da amostra em forma dos seus respectivos ácidos voláteis ou $\mathrm{SO}_{2} \mathrm{e}$ $\mathrm{SO}_{3}$, no caso do enxofre. Estes são transportados até um condensador ou recipiente contendo uma solução absorvedora para a sua determinação. Como a solução resultante não tem muitos sólidos dissolvidos ou soluções ácidas concentradas, esta pode ser adequada para a análise direta. Com essa separação do analido da matriz é minimizado possíveis interferências na etapa de determinação do analido. 
Na sequência foi utilizado o método espectofotométrico com adaptação de análise por injeção de fluxo (FIA). Nesse sistema, a amostra é introduzida em um fluído carregador que permite seu transporte até o detector. Esse sistema visa acelerar e tornar as análises mais seguras, principalmente por que algumas análises são feitas utilizando reagentes tóxicos e de baixa estabilidade.

Para as amostras, foi utilizado o cimento Portland pozolânico e o de alta resistência inicial, e os resultados dessa análise foram de acordo com trabalhos deportados na literatura. Os resultados foram os seguintes:

Tabela 02 - Concentração de cloreto (resultado em $\mu \mathrm{g} \mathrm{g}^{-1}$, correspondente à média \pm desvio padrão, $\mathrm{n}=3$ ).

\begin{tabular}{cc}
\hline Amostras & Valor determinado \\
\hline CP IV 32 a & $464 \pm 54$ \\
\hline CP IV 32 b & $127 \pm 13$ \\
\hline CP V ARI a & $132 \pm 19$ \\
\hline CP V ARI B & $147 \pm 5$ \\
\hline
\end{tabular}

Fonte: Duarte et al., (2013).

As concentrações encontradas das amostras de cimento foram abaixo dos limites máximos permitidos por diversas normas, que tem valor máximo de cloreto em cimento seco em geral de 4000ug g-1. E menores que aí da normal norte americana a Federal Highway Administration (FHWA), que estabelece limite de até 3000 ug g-1 de cloreto para cimento seco. A Associação Brasileira de Norma Técnica ainda não reporta limites para cloreto em cimento (Duarte; Pereira; Flores; Muller; Flores; Dressler, 2013).

De acordo com Gentil (2014) existem fatores que ajudam a limitar o teor de íon cloreto livre em uma estrutura de concreto, como, por exemplo, cimentos com maior concentração de $\mathrm{C}_{3} \mathrm{~A}$ e $\mathrm{C}_{4} \mathrm{AF}$, já que ocorre uma reação entre o cloreto com o aluminato do concreto, formando o cloroaluminato de cálcio. Com isso, ocorre uma diminuição no processo corrosivo da estrutura, pois diminui os íons de cloretos livres (responsáveis pela corrosão), obtendo íons de cloreto conjugado. Por isso esse cimento é o mais recomendado em regiões litorâneas.

Existe uma grande complexidade quando se refere ao teor de cloreto, pois, para o mesmo teor de cloreto encontrado em estrutura, pode haver corrosão ou não, uma vez que existem fatores que favorecem a corrosão, como, por exemplo, a migração do íon de cloreto na massa de concreto, pode gerar pequenos teores concentrados, mas podendo ser mais perigoso que grandes concentrações homogêneas e uniformemente distribuídas (IPT, 1978 apud HELENE, 1986). 
Existe um consenso entre autores sobre o valor máximo do teor de cloreto, segundo Helene (1986), que é no máximo $0,03 \%$ para concreto protendido a 2,00\% para concreto armado em relação à massa de cimento.

\subsection{ENSAIO PARA DETERMINAR A TEMPERATURA ALCANÇADA PELA HIDRATAÇÃO DO CIMENTO}

Utilizando valores possíveis para o laboratório, com a relação água cimento de 0,5 , foram medidos $20 \mathrm{~g}$ de soluto (cimento) para $10 \mathrm{ml}$ de solvente (água destilada); na sequência, foram dobrados seus valores, de $40 \mathrm{~g}$ de soluto para $20 \mathrm{ml}$ de solvente. Foram medidas com termômetro as temperaturas que a massa de cimento alcançava pela sua hidratação, conforme dados mostrados no gráfico 1:

Gráfico 1 - Variação da temperatura pela hidratação do cimento

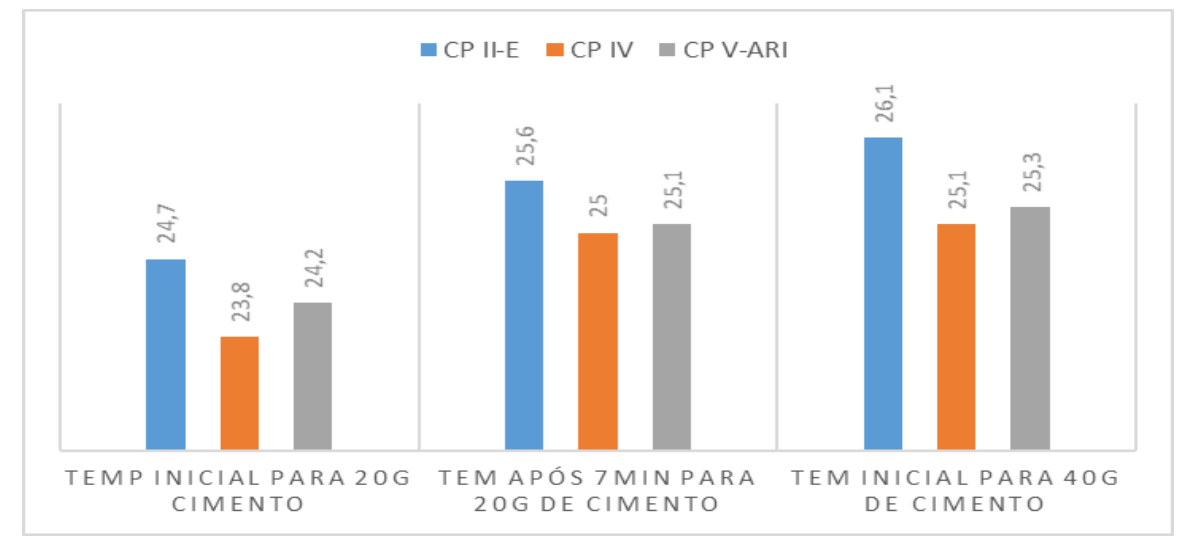

Fonte: Autores (2017).

Desejou-se simular o aumento da temperatura como sendo no canteiro de obras, porém, não houve um aumento significativo, se assemelhando a temperatura do próprio ambiente.

A partir desses dados, pode-se perceber que não houve uma grande variação de sua temperatura, uma vez que o volume da pasta de cimento produzido é muito pequeno, já que a quantidade de calor gerada pela hidratação é proporcional ao volume da pasta de cimento. Fato estes já relatados por outros autores (TARTUCE; GIOVANNETTI, 1990).

A determinação do fator água cimento é importante no controle do calor de hidratação, uma vez que o cimento é o gerador do calor; então a sua quantidade é crucial para esse aumento de temperatura da pasta ou concreto (GAMBALE, 2010). 
A finura do cimento também é um fator determinante para a hidratação do mesmo. Pois quanto menor sua granulometria, mais veloz será sua reação. $O$ que determina essa menor granulometria do cimento é o tempo de moagem do clínquer, em consequência irá obter um cimento mais caro e com um maior calor de hidratação. O exemplo deste tipo de cimento é o cimento de alta resistência inicial (LIDUÁRIO, 2006).

Cimentos que possuem aditivos minerais (como escória de alto forno e pozolana, por exemplo) são aqueles que têm menor calor de hidratação, pois a pozolana, por exemplo, apresenta uma taxa de reação lenta, ou seja, libera calor de forma lenta e o desenvolvimento de resistência também é lenta. As adições minerais são um produto, em si próprio, cimentante; mas em presença de água reagem com a cal, formando um produto com propriedades cimentantes (LIDUÁRIO, 2006).

A tabela a seguir mostra o calor de hidratação de cada tipo de cimento, medidos em estudos no laboratório de concreto de FURNAS CENTRAIS ELÉTRICAS S.A:

Tabela 03 - Calor de hidratação dos tipos de cimento Portland (banco de dados do laboratório de Furnas).

\begin{tabular}{lcc}
\hline \multirow{2}{*}{ Tipos de cimento } & \multicolumn{2}{c}{ Calor de Hidratação (J/g) } \\
\cline { 2 - 3 } & \multicolumn{2}{c}{ Idade (dias) } \\
\cline { 2 - 3 } CP II - E & $\mathbf{3}$ & $\mathbf{7}$ \\
\hline & 241 & 258 \\
\hline CP- IV & & 212 \\
& $207-235$ & - \\
CP-V & & 258 \\
\hline
\end{tabular}

Fonte: Liduário (2006).

De acordo com a norma NBR 13116 (ABNT, 1994), o cimento que apresenta um baixo calor de hidratação é aquele que apresenta um calor de hidratação de $260 \mathrm{~J} / \mathrm{g}$ aos 3 dias e de $300 \mathrm{~J} / \mathrm{g}$ aos 7 dias.

\section{CONCLUSÃO}

Buscando a prevenção de patologias em estruturas de concreto, este artigo teve como objetivo o estudo físico e físico-químico da pasta de cimento dos diferentes tipos comercializados na cidade de São Luís, Maranhão. 
A importância do $\mathrm{pH}$ do cimento, sendo ele crucial para a criação da película passivadora do concreto, é fundamental na proteção da armadura da estrutura contra agentes agressivos externos, como, por exemplo, o íon cloreto e o sulfato.

O teor de cloreto no cimento não causa patologias em si, uma vez que a quantidade é pequena. O problema está na fabricação, por exemplo, de uma estrutura de concreto armado ou protendido, pois quando se misturam os aglomerantes, aglomerados, água de abatimento, acaba aumentando o seu teor, podendo causar patologias. Esse íon pode ser adicionado em concreto, como aditivo para aumentar a velocidade de endurecimento. Por isso, é necessária essa análise.

O calor de hidratação pode tornar-se um problema em construções em que utiliza volumes muito grandes na concretagem de uma peça, por exemplo. Como o calor de hidratação é diretamente proporcional ao volume de concreto ou massa, esses volumes grandes causam dilatação térmica que, quando retornarem ao volume original, pois já vai ter dissipado a energia, irá criar fissuras internas, podendo criar um colapso na estrutura. Por isso, faz-se necessário o conhecimento desse processo, a fim de serem tomadas medidas que diminuam o seu impacto.

\section{REFERÊNCIAS}

ASSOCIAÇÃO BRASILEIRA DE CIMENTO PORTLAND. Guia básico de utilização do cimento portland. 7. ed. São Paulo, 2002.

ASSOCIAÇÃO BRASILEIRA DE NORMAS TÉCNICAS. NBR 5733: Cimento portland de alta resistência inicial. Rio de Janeiro, 1991.

NBR 5736: Cimento portland pozolânico. Rio de Janeiro, 1991.

NBR 7211: Agregados para concreto - especificações. Rio de Janeiro, 2005.

NBR 11172: Aglomerantes de origem mineral. Rio de Janeiro, 1990.

NBR 11578: Cimento portland composto. Rio de Janeiro, 1991.

1994.

NBR 13116: Cimento portland de baixo calor de hidratação. Rio de Janeiro,

CARNEIRO, Guilherme Victor Humberto Soares; GIL, Leonardo Koziel dos Santos; CAMPOS NETO, Manoel Pires. Calor de hidratação no concreto. 2011. 67 f. TCC (Graduação) - Curso de Engenharia Civil, Universidade Federal de Goiás, Goiânia, 2011.

DUARTE, Fabio A. et al. DETERMINAÇÃO ESPECTROFOTOMÉTRICA DE CLORETO 
EM CIMENTO APÓS PREPARO DE AMOSTRA POR PIROIDRÓLISE. Rio Grande: Quim Nova, 2013.

FRANÇA, Clério Bezerra de. Avaliação de cloretos livres em concretos pelo método de aspersão de solução de nitrato de prata. 2011. 105 f. Dissertação (Mestrado) Curso de Engenharia Civil, Universidade Católica de Pernambuco, Recife, 2011.

GENTIL, Vicente. Corrosão. Rio de Janeiro: Ltc, 2014.

HELENE, Paulo R. L.. Corrosão em estruturas armadas para concreto armado. São Paulo: Pini, 1986

LIDUÁRIO, Alfredo Santos. Contribuição ao estudo das propriedades térmicas do concreto convencional na presença das adições minerais. 2006. 260 f. Dissertação (Mestrado) - Curso de Engenharia Civil, Universidade Federal de Goiás, Goiânia, 2006.

MEHTA, P. Kumar; MONTEIRO, Paulo J. M.. Estrutura, propriedades e materiais. São Paulo: Pini, 1994.

SOUZA, Vicente Custódio Moreira de; RIPPER, Thomaz. Patologia, recuperação e reforço de estruturas de concreto.São Paulo: Pini, 1998.

TARTUCE, Ronaldo; GIOVANNETTI, Edio. Princípios básicos sobre concreto de cimento portland. São Paulo: Pini, 1990. 